\title{
Erratum to: MicroRNA-21 in Scleroderma Fibrosis and its Function in TGF- $\beta$ - Regulated Fibrosis-Related Genes Expression
}

\author{
Honglin Zhu • Hui Luo • Yisha Li • Yaou Zhou • Ying Jiang • \\ Jin Chai • Xianzhong Xiao • Yunhui You • Xiaoxia Zuo
}

Published online: 18 June 2013

(C) Springer Science+Business Media New York 2013

Erratum to: J Clin Immunol (2013)

DOI 10.1007/s10875-013-9896-Z

The original publication of this article contained incorrect statistical charts in Figure 1. These have been corrected in the figure below.

The online version of the original article can be found at http://dx.doi.org/ 10.1007/s10875-013-9896-z.

H. Zhu $\cdot$ H. Luo $\cdot$ Y. Li $\cdot$ Y. Zhou $\cdot$ Y. Jiang $\cdot$ J. Chai $\cdot$

Y. You $(\bowtie) \cdot X$. Zuo $(\bowtie)$

Department of Rheumatology, Xiangya Hospital,

Central South University, 87 Xiangya Road,

Changsha, Hunan 410008, People's Republic of China

e-mail: youyunhui@yahoo.com.cn

e-mail: susanzuo@hotmail.com

\section{Xiao}

Department of Pathophysiology, Xiangya School of Medicine,

Central South University, 110 Xiangya Road,

Changsha, Hunan 410008, People's Republic of China 
A
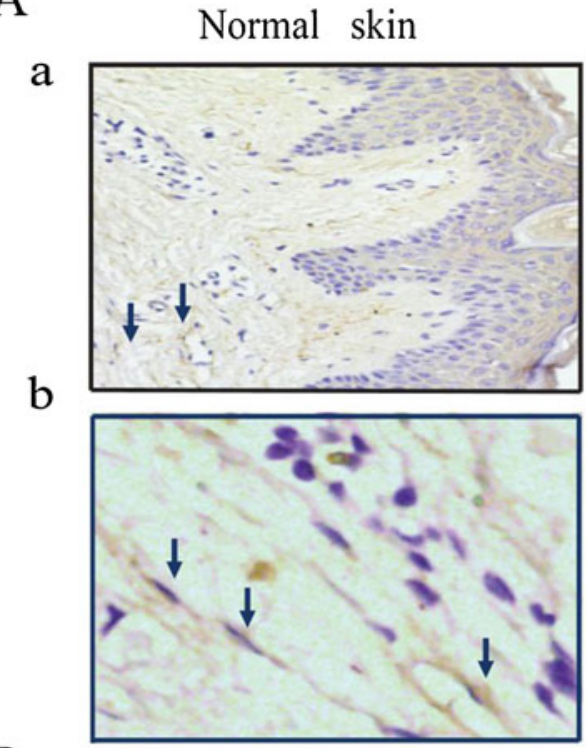

B

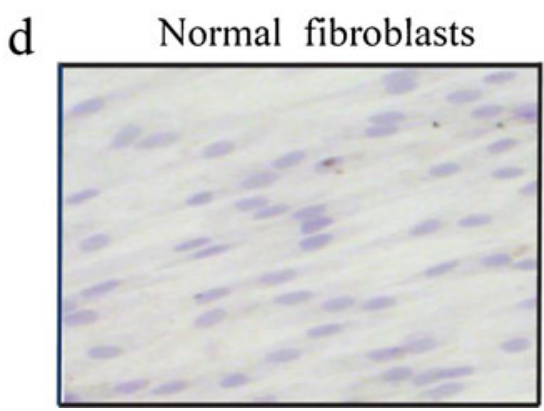

SSc skin
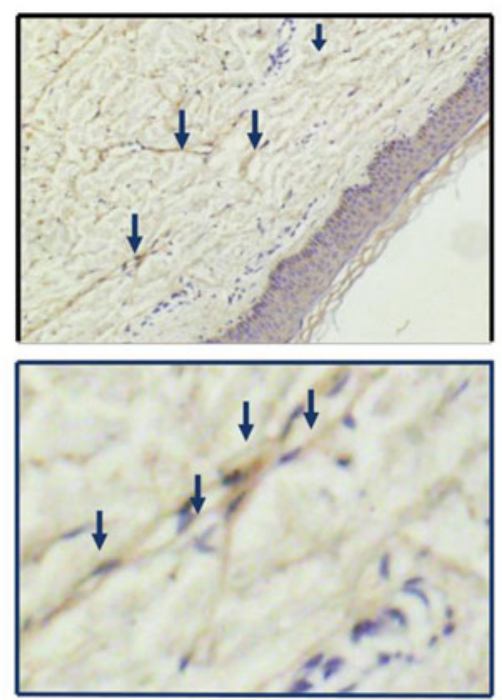

c

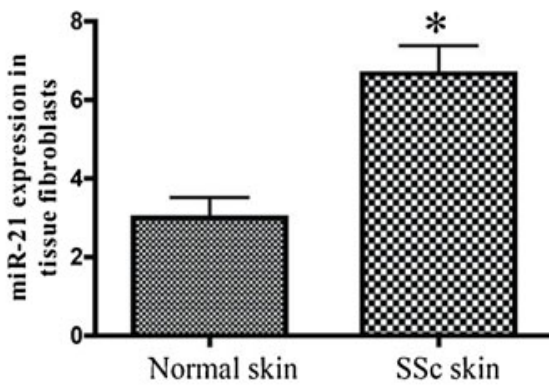

SSc fibroblasts

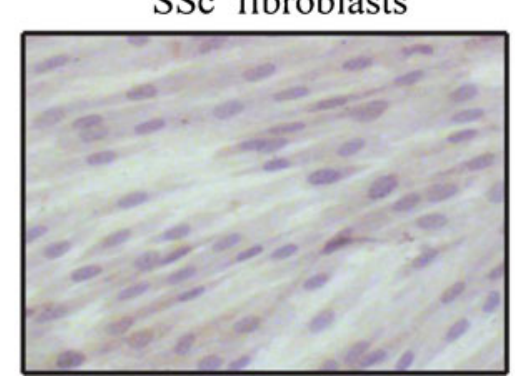

e

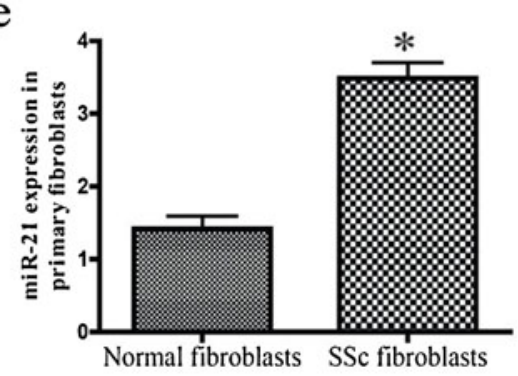

Fig. 1 